\title{
PROPOSTA DE CRIAÇÃO DE ROTEIRO DE HQ SINALIZADA PARA CULTURA SURDA
}

\author{
A proposal to create signed $H Q$ screenplays for the deaf culture
}

Ivan de SOUZA ${ }^{1}$

Licenciando, Letras Libras, Universidade Federal do Paraná hiven89@gmail.com

Kelly Priscilla Lóddo CEZAR Universidade Federal do Paraná kellyloddo@ufpr.br

\begin{abstract}
RESUMO²: O presente artigo tem por objetivo apresentar uma proposta de criação de roteiro para elaboração de uma HQ bilíngue para surdos. A investigação se justifica por se tratar de línguas minoritárias visuais que demandam o pleno conhecimento da estrutura linguística e da cultura surda a fim de respeitar de fato os artefatos culturais dessas línguas. Junto a isso, mesmo pertencendo a comunidade surda, no momento de criação da HQ sinalizada da cultura indígena terena, sentimos limitações. Com o intuito de incentivar e de auxiliar novas pesquisa na área, em especial, de criação de HQs sinalizadas, optamos por um estudo de caso em que selecionamos a HQ "O congresso de Milão" (CEZAR, ALMEIDA, 2018) para entrevistar individualmente o desenhista-roteirista com o intuito de descrever e de organizar uma proposta metodológica a partir de suas respostas para criação de uma história em quadrinhos da língua de sinais terena. Os resultados revelaram: a) extrema necessidade do desenhista pertencer a cultura surda b) o roteiro ser acessível nas línguas em que se propõe divulgar o trabalho; c) deve ter riqueza de detalhes quando a ilustração será feita por outro profissional d) quando se pensa na comunidade surda como público, deve conter riqueza de expressões não verbais. PALAVRAS-CHAVE: Línguas De Sinais; Hq Sinalizada; Roteiro; Povo Terena.
\end{abstract}

ABSTRACT: The purpose of this article is to present a proposal for guidelines for the preparation of a bilingual comic book for the deaf. The investigation is justified because they are visual minority languages

\footnotetext{
${ }^{1}$ Pesquisador da Iniciação Científica (PIBIS - CONVÊNIO No 169/2019 FA/UFPR).

${ }^{2}$ Resumo disponível em Libras $<$ https://youtu.be/0YVIrv4GLTU $>$.
} 
that demand full knowledge of the linguistic structure and deaf culture in order to respect in fact with the cultural artifacts of those languages. Along with this, even though they belong to the deaf community, at the time of the creation of the HQ marked by the indigenous Terena culture, we felt many difficulties. In order to encourage and assist new research in the area, especially in the creation of signage comics, we opted for a case study in which we selected the comic "The Milan Congress" (CEZAR, ALMEIDA, 2018) to interview the designer individually and screenwriter in order to describe and organize a methodological proposal for creating a comic book in the Terena Sign Language. The results revealed that a) the artist's extreme need to belong to the deaf culture b) the script must be accessible in the languages in which he proposes to disseminate the work c) he must have a wealth of details when the illustration will be done by another professional d) when thinking about deaf community as a public, must contain a wealth of non-verbal expressions. KEYWORDS: Sign Languages, Signed Graphic Novel, Script, Terena People.

\section{INTRODUÇÃO}

A presente investigação busca contribuir com orientações essenciais para elaboração de roteiro que visam à criação de histórias em quadrinhos sinalizadas bilíngues para surdos. O interesse pelo estudo se deu por perceber a importância de valorizar línguas minoritárias, em especial, as línguas indígenas sinalizadas. $\mathrm{O}$ fato de pertencer à comunidade surda urbana brasileira - usuária da língua brasileira de sinais (libras) - e estar cursando a licenciatura em letras-libras pela Universidade Federal do Paraná (UFPR), faz-me pensar e repensar sobre a importância de pertencer e se envolver com os artefatos culturais para produção de materiais sinalizados. Adentrei aos estudos da linguística aplicada ao ensino intermediado pelo grupo de pesquisa Formação de professores em línguas estrangeiras (UFPR) na área de formação de professores de libras via o projeto de pesquisa gêneros textuais e o ensino para surdos que estudam e criam histórias em quadrinhos bilíngues para comunidade surda.

Iniciei, em 2018, os estudos teóricos sobre a construção de narrativas visuais como instrumento de ensino para surdos sobre a história e a cultura das línguas de sinais indígenas terena e guarani. Nela, objetivamos criar uma história em quadrinhos envolvendo a língua de sinais terena para valorização e para preservação da cultura e história do povo terena, bem como da língua de sinais de que fazem uso os indivíduos surdos pertencentes a essa comunidade. Os dados apresentados neste estudo é um recorte 
do projeto de pesquisa sobre narrativas visuais e a cultura indígena que teve duração de dois anos, financiada pela Fundação Araucária (PIBIS-FA-UFPR) que resultou na criação da Hq terena sinalizada "Kaxe a koixomuneti surda" que significa em português "Sol: a pajé surda" ${ }^{3}$.

A criação de histórias em quadrinhos sinalizadas se deve pela comunidade surda fazer uso da predominante da comunicação viso-gestual que vão ao encontro da estratégia de utilizar narrativas visuais - linguagem dos quadrinhos - para tratar da história do povo terena, tendo como umas das bases o trabalho de Bittencourt e Ladeira 2000, que se faz uma forma de preservar o passado desse povo através de histórias em quadrinhos, bem como torná-la acessível aos surdos dessa comunidade e a quem possa interessar.

Neste trabalho, investigamos sobre a comunidade terena oral e os indivíduos surdos que utilizam a sua uma língua própria - língua de sinais terena, buscamos identificar se há influência da libras - língua sinalizada urbana e regulamentada - na sinalização terena por meio de estudos bibliográficos (FARGETTI, 2012; OLIVEIRA; FERREIRA, 2013; SILVA, 2013; SOUZA, 2016; SUMAIO, 2014, 2018; VILHALVA, 2018).

O presente trabalho objetivou-se de uma forma mais ampla buscar uma estratégia visual para atingir o objetivo de registrar e preservar a história, a cultura e a língua de sinais do povo terena da comunidade terena brasileira, não só por meio de quadrinhos, mas também pela criação em vídeo de um sinalário e um glossário com alguns dos sinais existentes e registrados na comunidade, bem como de termos que não possuem sinais e que são utilizados durante a pesquisa. No entanto, no momento da criação, percebemos as dificuldades de compreensão por parte do desenhista que aceitou produzir o trabalho, mas não pertencia a nenhuma comunidade surda. A partir das dificuldades, mesmo com muito esforço, entrevistamos e analisamos as respostas do roteirista-desenhista sinalizante Luiz Gustavo Paulino de Almeida, autor da HQ "O congresso de Milão" para auxiliar na criação de roteiros de história em quadrinhos sinalizadas.

As línguas de sinais são consideradas línguas de minorias, quando nos reportamos às línguas indígenas e as línguas indígenas sinalizadas este universo se torna mais distante do que pensamos. Durante os estudos nos deparamos com os dados sobre o panorama da diversidade linguística no Brasil, o qual o censo do IBGE 2010 aponta para 274 línguas faladas por indígenas de 305 etnias diferentes. Esse número levantado pelo IBGE teve como base a autodeclaração de indígenas, quando perguntados sobre "qual a língua falada em casa?". Ainda, conforme o censo, cerca de metade das línguas possuem menos de cem

\footnotetext{
${ }^{3}$ A publicação física da HQ depende de financiamento e deve ser publicada em agosto de 2020.
} 
falantes. As línguas com até quinhentos (500) falantes somam pouco mais de um terço de todas as línguas indígenas. Outro dado importante é de que menos de dez por cento $(10 \%)$ dessas línguas possuem mais de dois mil falantes. Mesmo hoje persiste socialmente a ideia do Brasil como país monolíngue e a falta de conhecimento e valorização, por meio do preconceito social existente, leva a exclusão dessas línguas minoritárias tornando até invisíveis as línguas indígenas sinalizadas.

O INDL (Inventário Nacional da Diversidade Linguística), que é o atual instrumento oficial de identificação, documentação, reconhecimento e valorização das línguas faladas pelos diferentes grupos formadores da sociedade brasileira, implantou no ano de 2017, o Inventário Nacional da Língua Brasileira de Sinais que faz parte da Política da Diversidade Linguística. Esse trabalho é fundamental para a valorização e continuidade deste valioso bem cultural brasileiro e da diversidade linguística. Além de fomentar a produção de conhecimento sobre as línguas faladas no Brasil e contribuir para a garantia de direitos linguísticos.

A preservação de uma língua, conforme o IPHAN (Instituto do Patrimônio Histórico e Artístico Nacional) por meio de seu Guia de Pesquisa para o INDL (2014), tem impacto imediato na perda de diversidade cultural, uma vez que cada língua possui os meios específicos, historicamente construídos de se conceber, conhecer e agir sobre o mundo, incluindo conhecimentos altamente técnicos.

Após levantamento em base de dados especializadas, as existências de outros projetos com o mesmo objetivo não foram localizados. Este trabalho possui, portanto, uma grande relevância social, acadêmica e científica. Os resultados podem influenciar na construção e criação de materiais similares para essa minoria linguística.

Optamos por trabalhar com criações de história em quadrinhos, por ser um gênero híbrido visual e de fácil identificação com a cultura surda e por ser um gênero que ainda não foi explorado na comunidade terena. Nas palavras, Guimarães (1999, p. 6), define histórias em quadrinhos como sendo:

[...] toda produção humana, ao longo de toda sua História, que tenha tentado narrar um evento através do registro de imagens, não importando se esta tentativa foi feita numa parede de caverna há milhares de anos, numa tapeçaria, ou mesmo numa única tela pintada. Não se restringe, nesta caracterização, o tipo de superfície empregado, o material usado para o registro, nem o grau de tecnologia disponível. Engloba manifestações na área da Pintura, Fotografia, principalmente a fotonovela, do Desenho de Humor como a charge, o cartum, e sob certos aspectos, a caricatura, e até algumas manifestações da Escrita, 
como as primeiras formas de ideografia, quando o nível de abstração era baixo e ainda não havia uma correspondência entre símbolos escritos e os sons das palavras.

Como em sua maioria trata-se de línguas ágrafas ou que tem uma escrita pertencente a uma cultura minoritária, criar uma história em quadrinhos para esse público torna-se uma estratégia emancipatória tanto para cultura quanto para os que estão de fora.

\section{PRESSUPOSTOS TEÓRICOS}

As línguas de sinais tiveram seu estatuto linguístico reconhecido mundialmente na em 1960, conforme Quadros (2009), foi por intermédio, do pesquisador e linguista William Stokoe, que elaborou uma descrição da Língua de Sinais Americana (ASL). No Brasil, a língua brasileira de sinais foi reconhecida como meio legal de comunicação dos sujeitos surdos em 2002 quando se deu a criação da lei n ${ }^{0}$ 10.436. Em dezembro de 2005, cria-se o decreto $\mathrm{n}^{0} 5.626$, que estabelece a inclusão da Libras como disciplina obrigatória nos cursos de formação de professores para o exercício do magistério em nível médio e superior, e nos cursos de fonoaudiologia das instituições públicas e privadas, bem como na formação do professor e do instrutor de Libras e também na formação do tradutor e intérprete de Libras, entre outros temas de relevância na área.

Um fato recente acerca a libras ocorreu na posse do atual presidente, Jair Bolsonaro, em que a primeira dama, Michelle Bolsonaro, quebrou o protocolo ao discursar em Libras antes de seu marido no Palácio do Planalto. Em entrevista à folha de São Paulo (2019), ela afirmou ter o objetivo de lutar e defender minorias como a comunidade surda, além de pessoas com deficiências e doenças raras. Ainda segundo ela a posse gerou aumento no interesse pela Libras.

Embora o Brasil conte com 225 etnias indígenas que falam 170 línguas orais, há apenas uma língua de sinais registrada - a Língua de Sinais Ka'apor. Conforme Kakumasu (2005) e posteriormente Sumaio (2014), nesse grupo indígena, há algumas décadas, houve uma epidemia de bouba neonatal que resultou em surdez nos bebês. Estas crianças e seus familiares, portanto, criaram, sem influência externa alguma, uma língua de sinais própria. Esta é utilizada por toda a comunidade, tanto por ouvintes quanto por falantes, sendo toda a sociedade bilíngue.

De acordo com os dados apresentados, observa-se que as línguas de sinais têm estudos recentes, tal língua é considerada língua de minoria. Em consonância com esses 
dados, nesta mesma esteira de pensamento encontramos as línguas indígenas, revelando uma fragilidade imensa em um contexto das maiorias linguísticas.

Seguindo essa linha de pensamento, mesmo para a comunidade indígena ouvinte, a conquista por direito a receber educação em suas próprias línguas nativas - conforme capítulo VIII, da Constituição Federal, conforme nos lembra Delmondez e Paulino (2014), o atual paradigma denominado emancipatório, pautado na interculturalidade e no bilinguismo - só foi conquistado há vinte anos, a partir das conquistas do movimento político dos povos indígenas (MAHER, 2006).

Isso se torna ainda mais difícil de ser cumprido quando se trata das línguas de sinais indígenas que são também naturais, porém não tem sua existência valorizada e reconhecida. Alguns trabalhos merecem destaque, sendo: Variação linguística na escola: resultados de um projeto, Baronas (2014)Políticas de línguas e educação escolar indígena no Brasil, Cunha (2008), Abordagens sobre o léxico em línguas indígenas, Fargetti (2012) e destacamos a pesquisa que mais se aproximou do objetivo do presente trabalho: Língua terena de sinais: análise descritiva inicial da língua de sinais usada pelos terena da Terra Indígena Cachoeirinha (SUMAIO, 2018), em que constatou-se terena surdos na Comunidade Indígena de Cachoeirinha, de 9.507 habitantes e também em aldeias vizinhas, próximas ao município de Miranda-MS. E grande parte desses sujeitos não conhece a língua brasileira de sinais, mas utiliza sinais próprios o que caracteriza uma língua nativa de sinais.

Conforme Sumaio (2014, p. 6), alguns nunca frequentaram a escola ou tiveram contato com surdos usuários de libras o que nos leva a crer que não foram influenciados na criação dos sinais nativos. Além disso, constatou-se que: ' 'alguns jovens estudam na cidade e estão avançando no uso e conhecimento da libras, porém estes mesmos jovens utilizam outros sinais na aldeia, com seus familiares ouvintes, amigos e outros surdos, que não sabem libras".

Com base nessas informações, pretendemos levar esses dados as culturas envolvidas, em especial, para a cultura surda brasileira a fim de assegurar e transmitir as línguas sinalizadas e os conhecimentos que nela envolvem. Dessa forma, pretendemos com os resultados da investigação de como criar um roteiro para criação de uma HQ em libras adaptar e exaurir para outras comunidades sinalizadas respeitando as diferenças linguísticas, culturais e históricas de cada uma. 


\section{METODOLOGIA}

Para atender ao objetivo proposto, optou-se por um estudo de caso. Conforme a classificação de Ventura (2007, p.384), é entendido como uma metodologia ou como a escolha de um objeto de estudo definido pelo interesse em casos individuais. Visa à investigação de um caso específico, bem delimitado, contextualizado em tempo e lugar para que se possa realizar uma busca circunstanciada de informações.

Para tanto, foi realizado entrevista semiestruturada com a participação, voluntária do roteirista-desenhista da HQ “O congresso de Milão" Luiz Gustavo Paulino de Almeida, a escolha desse ilustrador se deu em razão de ter publicado a primeira HQ bilíngue em nível de resultado de pesquisa (CEZAR, ALMEIDA, 2018).

A entrevista ${ }^{4}$ acerca do tema, contou com seis perguntas, com duração de aproximadamente 45 minutos, sendo elas: 1) Como você criou o roteiro da $\mathrm{HQ}$ "O congresso de Milão"?; 2) Quais foram os roteiros, os autores que deram suporte na criação do roteiro?; 3) Quais foram as principais dificuldades encontradas na criação do roteiro?; 4) Quais foram as principais características ou cuidados que você teve de ter na criação do roteiro?; 5) Quais são as sugestões ou direcionamento da elaboração de um roteiro para criação de HQs bilíngues?;6) Quais informações não podem faltar no roteiro para auxiliar o desenhista? Por meio das respostas se criou dicas para futuras produções com o mesmo objetivo.

Com base no trabalho realizado sobre a comunidade terena percebemos que quando se trata de criação de uma HQ bilíngue se faz imprescindível: a criação de sinalário que é feito com pesquisa de sinais já documentados e, quando esses não forem localizados, criação de novos sinais; pouca verbalização focando mais nos detalhes visuais da cena e expressões faciais; não são usados balões, pois as informações ficam contidas nas expressões não verbais ou na sinalização dos personagens e a sinalização em língua de sinais da história proporcionando ao público surdo total entendimento do conteúdo.

\footnotetext{
${ }^{4}$ A presente entrevista foi gravada em língua brasileira de sinais a fim de se transformar em um acesso linguístico para comunidade surda (libras). A opção por não apresentar em língua de sinais terena se deu em razão de questões temporais não ter sido possível a aprovação em tempo hábil pelo comitê de ética em pesquisas. No entanto, a tradução em língua terena escrita já está sendo providenciada.
} 


\section{APRESENTAÇÃO E DISCUSSÃO DOS RESULTADOS}

Quando se trata de criação de HQs voltados para o público ouvinte, conforme Brandão (2017), os quadrinhos são a junção de texto e imagem, para o pesquisador não existe quadrinhos em texto existem em quadrinhos mudos sem balões onomatopéias ou recordatórios, mas nunca sem texto nesses o texto está implícito é o roteiro a história que guia todas as decisões narrativas estéticas do autor, um quadrinista é antes de tudo um contador de história. Para Danton (2008), o roteiro de uma HQ precisa ser dividido em dois aspectos: a) conteúdo e b) forma. O conteúdo é a história em si, a trama e o plot. A forma agrupa os recursos de texto usados para contar essa história (GLERIA, 2010).

Em consideração aos pressupostos teóricos que salientam como se cria um roteiro para criação de história em quadrinhos, optamos por compreender a diferença e similaridade para criação de uma história em quadrinhos ou narrativas visuais tendo a cultura surda como enfoque de criação.

A partir das respostas realizamos uma categorização dos dados para propor como roteirização para futuros ilustradores de história em quadrinhos que envolvem os artefatos culturais do povo surdo (GESSER, 2009).

\section{1 - Como você criou o roteiro da HQ "O Congresso de Milão"?}

$R$ : O processo de criação do roteiro da $H Q$ "O Congresso de Milão" foi trabalhoso, uma vez que não havia feito um trabalho grande voltado para o gênero histórias em quadrinhos. Apesar de crescer lendo revistas e mangás, nunca produzi uma narrativa visual. A criação da HQ foi bastante desafiadora. Diferente da elaboração de roteiros convencionados mundialmente, realizei a sequência dos requadros e desenhos de forma visual sinalizada, através de esboços em papel sulfite ou cadernos. As primeiras quatro páginas renderam duas apresentações em nível acadêmico e um artigo publicado em periódico. O roteiro (piloto) demorou meses para ser feito, pois o processo era lento. Primeiro a ideia em imagem mental e depois expressar essa ideia no papel sulfite. Feito isso, partia para a segunda etapa: o preenchimento com caneta nanquim. Esse periodo do material esboçado para o preenchimento da arte, além do tempo, eu gastava muito com materiais. Foi então que passei para o desenho digital, comprando uma mesa digitalizadora e instalando o software Manga Studio 5.0. Desde então, finalizei o roteiro através dos esboços do próprio programa. 
A partir dessa resposta, observamos a importância de se pertencer a cultura surda, uma vez que como relata o ilustrador foi fruto de trabalhos científicos que duraram cerca de três anos e que pertence a comunidade surda, no entanto o trabalho maior se deu em destaque com a preocupação com desenhos "visual sinalizada". Além disso, observa-se que o fato de ter sido leitor de quadrinhos desde criança não foi suficiente para criação dos desenhos e dos requadros, já que as publicações existentes são voltadas para o público ouvinte e quando se pensa na comunidade surda os recursos existentes não se enquadram.

\section{2 - Quais foram os roteiros, autores que deram suporte na criação do roteiro?}

R: Para a criação do roteiro da HQ, autores como Will Eisner, Scott Mccloud, Stan Lee e Waldomiro Vergueiro foram fonte de pesquisa e inspiração da literatura especializada. Quanto aos traços e estilos me inspirei em roteiros de produções japonesas: os mangás.

Observa-se que a literatura especializada é de grande qualidade relacionando desde os principais autores na área até o ícone brasileiro Waldomiro Vergueiro.O estilo Mangá foi escolhido por mais destacar as expressões faciais das línguas de sinais. Na história em quadrinhos criada pelo ilustrador "O congresso de Milão" isso é possível ser visto, uma vez que em vários momentos o rosto ganha destaque em maior proporção que o corpo, em especial, nos momentos de conflitos com a proibição mundial das línguas de sinais.

\section{3 - Quais foram as principais dificuldades na criação do roteiro?}

$R$ : As dificuldades maiores que encontrei foram relacionadas a criação de um roteiro adaptado que atendesse as especificidades de uma cultura visual e que, de fato, levassem em conta os aspectos linguísticos das línguas de sinais: uma narrativa visual bilingue. Além de me ater na produção do roteiro (através dos esboços em frames digitais) precisei pensar em algo mais visual, contando com os pontos gramaticais da libras.

Compreender a cultura de uma língua, e os aspectos gramaticais das línguas de sinais, em especial, na língua brasileira de sinais. Conforme Quadros, Pizzio, Rezende, (2009) os sinais são produzidos com uma combinação de três categorias lingüísticas sem significado: configuração de mão, locação e movimento. Apresentam dois tipos de morfologia: simultâneo e o seqüencial cada um caracterizado por um conjunto diferente de 
propriedades. As expressões faciais têm, entre suas funções, marcar estruturas gramaticais específicas (como orações relativas), servindo para distinguir funções lingüísticas, uma característica única das línguas de modalidade visual-espacial.

\section{4 - Quais foram as principais características ou cuidados que} você teve de ter na criação do roteiro?

R: Para atender à proposta de uma $H Q$ bilingue, levei em conta retratar e deixar em evidência muitos traços da cultura surda. A narrativa possui em sua estrutura os mesmos aspectos das histórias em quadrinhos, porém, procurei ilustrar a língua sinalizada da forma mais clara possivel. Os aspectos não-verbais estão em maior proporção. Porém, mesmo assim se faz necessário a utilização dos aspectos verbais em pontos da narrativa, tanto na escrita da língua portuguesa como na fala sinalizada das personagens da HQ. O tema trabalhado "o Congresso de Milão" foi escolhido por se tratar de um tema de grande importância histórica. A proibição do modelo gestual francês foi um retrocesso para a educação dos surdos. Para retratar esse periodo a escolha das cores preto e branco foram propositais. As marcações nãomanuais estão em maior evidência, trabalhadas de forma sequencial durante toda a narrativa, buscando induzir o leitor à uma imersão na história. Porém, pensando atingir tanto um público ouvinte como um público surdo, a utilização dos textos em língua portuguesa e tradução desses textos em vídeo (libras) foram necessários, buscando quebrar a barreira linguística.

A partir da verbalização, observa-se que não há como não pensar em qualquer criação sem observar, refletir e aplicar a quebra da barreira linguística. Se não levado em conta a historicidade, a cultura e como promover a equidade linguística qualquer material estará fadado a não aplicabilidade na cultura surda. Pensar na proposta bilíngue é pensar na criação de sinalários, glossários e fazer um conjunto com a escrita da língua dominante e em especial os desenhos em que os leitores dessa comunidade se vejam presentes, ou seja, são personagens, são histórias narradas que trazem significados mesmo que em tom fictício.

\section{5 - Quais são as sugestões ou direcionamento da elaboração de um roteiro para criação de HQs bilíngues?}

R: Para a criação de uma HQ bilingue, se faz necessário buscar utilizar elementos não-verbais; trabalhar a visualidade caso seja preciso ilustrar falas sinalizadas. Atentar em um enredo que seja coerente e que atenda ao objetivo principal da narrativa. Além disso, o uso das 
expressões faciais são de grande valia por se tratar de um elemento gramatical das línguas sinalizadas. E, por fim, a quebra da barreira linguística através de traduções do texto em língua portuguesa para a libras.

Neste momento, salientamos que o ilustrador acaba por apresentar as etapas que seguiu e acabou criando um modelo a ser pensado sobre a criação de quadrinhos bilíngues como fonte de materiais disponíveis a essa cultura.

Os roteiros com foco no público ouvinte já se utilizam de recursos visuais para compor a narrativa, porém no que tange a comunidade surda o uso de recursos visuais é ainda mais necessário, principalmente quando se trata das expressões faciais e sinalizações.

\section{6 - Quais informações não podem faltar no roteiro para auxiliar o desenhista?}

R: Visando auxiliar o ilustrador no processo de produção de uma $H Q$, as informações necessárias que um roteiro deve conter são: o enredo com os detalhes da narrativa em cada requadro (mesmo os mínimos detalhes possiveis); as falas das personagens (no caso de uma $\mathrm{HQ}$ bilingue, adaptar os sinais de uma forma mais visual, buscando retratar a fala que destaque a ideia); outro elemento importante que não pode faltar é a sugestão de tom e preenchimento da narrativa.

Em consonância com as respostas obtidas na entrevista somadas as dificuldades que enfrentamos na criação do roteiro para criação de uma HQ sinalizada envolvendo a língua terena de sinais, elaboramos algumas dicas com o objetivo de nortear futuros trabalhos com a mesma finalidade. Concordando, com o escritor Marat (2006, p.29), "deve-se proporcionar ao desenhista os mínimos detalhes do que se quer para que este possa ter ideia exata do que se quer".

\section{COMO CRIAR UM ROTEIRO SINALIZADO}

Sabe-se das grandes dificuldades que há em criar um roteiro na área de história em quadrinhos, no entanto ao nos reportamos para uma área que conta com pouquíssimos materiais direcionados a cultura surda, esse obstáculo se mostra maior. No levantamento bibliográfico, identificamos que além de ser incipiente trabalhos dessa natureza, os quais encontramos acabaram por apresentar demasiadamente recursos escritos sem grandes referenciações à cultura surda, como personagens característicos e enredos bem marcados. 
O qual mais se aproximou foi a HQ "O congresso de Milão".

De acordo com Cezar (2018), o gênero história em quadrinhos pode se tornar um gênero em grande potencial para o processo bilíngue e para recursos disponíveis para transmissão dos saberes escolares, científicos e sociais para cultura surda, uma vez que a sintaxe dos quadrinhos vai ao encontro da sintaxe das línguas sinalizadas, que tem o recurso visual como fonte das informações primárias. Além do mesmo ser utilizado de forma multidisciplinar.

Imagem 1: Relação visual entre HQ/Línguas sinalizadas e os recursos visuais.

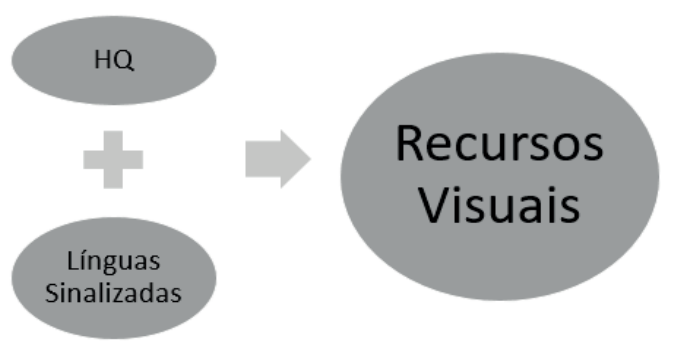

Fonte: Elaborado pelos autores.

Em consonância com as respostas obtidas, somadas as nossas experiências atuais, tanto na área de pesquisa quanto pertencente à comunidade surda, elenco brevemente os passos para se criar um roteiro sinalizado com o intuito de se tornar um recurso disponível para futuros roteiristas e ilustradores que envolvam as temáticas ou personagens surdos como ponto de referencial cultural.

\section{PROPOSTA DE UM ROTEIRO BILÍNGUE 5}

A presente investigação teve por objetivo levantar as principais características que um roteiro tem de apresentar uma história em quadrinhos bilíngue para comunidade surda e com as considerações do ilustrador investigado, apresentar as orientações para criação de novas histórias em quadrinhos sinalizadas, sendo que o maior destaque se revelou na importância de se pertencer a comunidade surda e ser sensível a mesma. Em nossos resultados, destacamos os seguintes aspectos:

\footnotetext{
${ }^{5}$ Disponível em libras: <https://youtu.be/asLde7Z12eA $>$.
} 
Quadro 1: orientações para criação de um roteiro sinalizado

1- Conhecer o público a que se destina a HQ: Esse é o primeiro ponto, pois se tratando da comunidade surda se faz necessário fazer parte dessa comunidade para ter conhecimento prévio de como o povo surdo adquire conhecimento; os elementos visuais necessários para transmitir as informações e trocar informações com surdos durante o processo de criação a fim de garantir que o objetivo será alcançado;

2- Dispor de referência teórica: Quando se trata da elaboração de uma HQ com conteúdo histórico, como é o caso da história do povo terena, se faz necessário pesquisar em diferentes fontes e autores que tratam do tema e não fazendo parte dessa comunidade específica buscar validar, com os nativos, se as informações estão em conformidade com a realidade por eles vivenciada;

3- Priorizar elementos visuais próprios da cultura surda como as expressões faciais, sinalizações e riqueza de detalhes. No caso de o roteirista não ser o ilustrador essas informações devem ser esmiuçadas no roteiro;

4- Criar glossário: com os sinais específicos que é uma forma de registrar e disseminar os sinais já existentes bem como criação de sinais, essa criação deve ser feita com cautela e após a não localização desse sinal específico em nenhum banco de dados;

5- Produzir a sinalização: da história para que seja acessível ao público usuário das línguas de sinais como forma de complementar e proporcionar a compreensão total do conteúdo trabalhado;

6- Por fim, ao que parece, ter paciência é a chave para a criação e desenvolvimento de uma HQ sendo ela destinada a comunidade surda ou ouvinte. Quanto ao ponto específico de criação pensando no público surdo se faz essencial o uso principalmente de imagens e não textos escritos já que esse público adquire e internaliza conhecimento de forma visual. Portanto os detalhes visuais bem como uso de imagens que remetem às experiências visuais vivenciadas culturalmente por essa comunidade não podem faltar.

Fonte: autores

A HQ "Kaxe a koixomuneti surda" conta a história e cultura do povo terena, essas são as considerações que utilizamos para desenvolvê-la. Contamos com um desenhista 
ouvinte não pertencente a comunidade surda e a partir dessa proposta apresentada os resultados foram satisfatórios. Portanto, torna-se importante destacar que ao iniciar um projeto que envolve culturas, requer mais zelo e cuidados na transposição das ilustrações - no caso da cultura terena sinalizada, observa-se a não necessidade de marcações expressivas, visto que a expressão facial não é considerada um marcador sintático, como na libras, por exemplo. Ao elaborar o roteiro buscamos estratégias visuais para que a ilustradora pudesse compreender mais claramente o que era esperado como resultado. Quando a criação de glossário e sinalário ${ }^{6}$ se mostrou importantíssimo para compreensão efetiva da história bem como forma de registro da sinalização e enriquecimento do léxico da língua sinalizada. E certamente a importância da pesquisa bibliográfica, criação de estratégias para a quebra da barreira linguística e a produção do roteiro propriamente dito foi essencial para o desenvolvimento do trabalho.

\section{CONSIDERAÇÕES FINAIS}

Os dados deste trabalho levam à conclusão de que quando se pensa em produzir uma HQ bilíngue se faz indispensável proporcionar ao(s) público(s) alvo(s) o entendimento do conteúdo criado, seja por meio de vídeos, textos ou imagens que serão por eles compreendido.

Seguindo as ideias postuladas por Brandão (2017), constatamos que quando se tem um roteirista que contará com outro profissional para realizar a arte, a comunicação deve ser mais eficaz. O roteirista deve fornecer, com riqueza de detalhes, o que está em sua mente para que o desenhista possa compreender e realizar a exteriorização do conteúdo em forma de imagem.

No levantamento bibliográfico identificamos escassez nos estudos e em materiais publicados com foco na produção de roteiros bilíngues voltados para a comunidade surda e esses sujeitos por sua vez acabam ficando submissos a língua majoritária ouvinte, o português. Portanto, a produção de materiais especializados em diferentes segmentos, e em especial na produção de HQs, reconhece o valor social da libras quebrando barreiras de comunicação e garantindo o real acesso a informações antes disponíveis apenas para ouvintes.

Os resultados da entrevista individual com o roteirista-desenhista da HQ: “O congresso de Milão", Luiz Gustavo Paulino de Almeida, foram ao encontro das

\footnotetext{
${ }^{6}$ Sinalário disponível em: $<$ https://www.youtube.com/watch?v=FS_ktXO2aGA>.
} 
dificuldades encontradas no caminho da criação da HQ sobre a história e cultura do povo terena e nos motivou a descrever e divulgar os cuidados/“orientação" sobre as culturas que têm as línguas visuais sinalizadas como fonte de conteúdo, junto a isso motivar novas pesquisas na área.

As orientações não se tratam de receita e nem de etapas a serem seguidas, mas um direcionamento para elaboração ou até mesmo análise de materiais didáticos que possam se transformar em recursos disponíveis para o ensino aprendizagem bilíngue da comunidade surda. 


\section{REFERÊNCIAS:}

ALMEIDA, L. G.; CEZAR, K. O congresso de Milão. Araraquara: Letraria, 2018.

BARONAS; J. E. Variação linguística na escola: resultados de um projeto. Revista da ABRALIN, v.13, n.1, p. 39-62, jan./jun., 2014.

BITTENCOURT; C. M.; LADEIRA, M. E. A história do povo Terena. Brasília : MEC, 2000 .

BRANDÃO, D. A linguagem dos quadrinhos. Universidade Federal do Ceará. 2017.

CUNHA, R. B. Políticas de línguas e educação escolar indígena no Brasil. Educar, Curitiba, n. 32, p. 143-159, 2008. Editora UFPR. Disponível em: $<$ http://www.scielo.br/ pdf/er/n32/n32a11.pdf>. Acesso em: 22 set. 2018.

DANTON, G. Roteiro para histórias em quadrinhos. São Paulo: All Print Editora, 2008.

DELMONDEZ, P.; PULINO, L. Z. Sobre identidade e diferença no contexto da educação escolar indígena. Psicologia \& Sociedade; 26(3), p. 632-64. 2014.

FARACO, C. A. Questões de política de língua no Brasil: problemas e implicações. Educar em Revista, n. 20, p. 13-22, 2002.

FARGETTI, C. M. (Org.). Abordagens sobre o léxico em línguas indígenas.Campinas, SP: Editora Curt Nimuendajú, 2012.

FOLHA DE SÃO PAULO. Vozes em extinção. Publicado em 25 set. 2007. Disponível em: $<$ https://super.abril.com.br/blog/planeta/vozes-em-extincao/>. Acesso em: 22 set. 2018.

GESSER, A. LIBRAS? Que língua é essa? Crenças e preconceitos em torno da língua de sinais e da realidade surda. Parábola Editorial, São Paulo, 2009.

GLERIA, E. As histórias em quadrinhos e a indústria cultural:aproximações à luz das criações de Maurício de Souza. 2010. 141 f. Dissertação (Mestrado em Letras) Universidade Presbiteriana Mackenzie, São Paulo, 2010.

GUIA DE PESQUISA E DOCUMENTAÇÃO PARA O INDL. Patrimônio Cultural de Diversidade linguística. Brasília, DF. IPHAN. 2014. Volume 1.

GUIMARÃES, E. Uma Caracterização Ampla para a História em Quadrinhos e seus Limites com Outras Formas de Expressão. Intercom 1999, Rio de Janeiro, 1999. 
KAKUMASU, J. Y. Urubu-Kaapor Sign Language. Summer Institute of Linguistics, 2005. Disponível em: <https://www.sil.org/resources/archives/76974>. Acesso em: 11 out. 2019.

MARAT, M. A palavra em ação: a arte de escrever roteiros para histórias em quadrinhos.

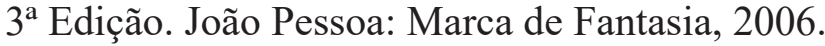

MAHER, T. M. A formação de professores indígenas: uma discussão introdutória. In: GRUPIONI (Org.). Formação de professores indígenas: repensando trajetórias. Brasília, DF: Ministério da Educação, Secretaria de Educação Continuada, Alfabetização e Diversidade; Rio de Janeiro: LACED/Museu Nacional, p. 11-38, 2006.

FOLHA DE SÃO PAULO. Michelle diz ter avisado Bolsonaro sobre discurso em Libras duas horas antes de sair para a cerimônia. 20 de jan. de 2019. Disponível em: <https:// www1.folha.uol.com.br/poder/2019/01/michelle-diz-ter-avisado-bolsonaro-sobrediscurso-em-libras-duas-horas-antes-de-sair-para-a-cerimonia.shtml $>$. Acesso em: 25 abr. 2019.

OLIVEIRA, C. P.; FERREIRA; R. V. Dicionário infantil bilíngue Terena-observações e apontamentos. Entre palavras, Fortaleza, Ano 3, v. 3, p. 89-101, 2013.

INVENTÁRIO NACIONAL DE LIBRAS. Publicado em: 10 jul. 2017. Disponível em: <http://portal.iphan.gov.br/indl/noticias/detalhes/4198/pesquisa-coleta-dados-parao-inventario-nacional-de-libras>. Acesso em: 24 mai. 2019.

QUADROS, R. M.; PIZZIO, A. L.; REZENDE, P. L. F. Língua Brasileira de Sinais I. Centro de Comunicação e Expressão. Florianópolis, 2009. Disponível em: <http://www. libras.ufsc.br/colecaoLetrasLibras/eixoFormacaoEspecifica/linguaBrasileiraDeSinaisI/ assets/459/Texto_base.pdf> Acesso em: 03 abr. 2019.

SOUZA, A. J.; CAMESCHI, C. Língua Terena: contribuições para sua documentação. Acadêmico do Curso de Licenciatura Intercultural Indígena Povos do Pantanal, da Universidade Federal de Mato Grosso do Sul, Campus de Aquidauana. Departamento de Letras - Universidade Federal de Mato Grosso do Sul. Disponível em: < http://www. letras.ufmg.br/lali/PDF/LINGUA\%20TERENA\%20relat\%C3\%B3rio\%20Aronaldo. pdf> Acesso em: 22 set. 2018.

SUMAIO, P. A. Sinalizando com os terena: um estudo do uso da LIBRAS e de sinais nativos por indígenas surdos. 2014. 123 f. Dissertação (mestrado) - Universidade Estadual Paulista Júlio de Mesquita Filho, Faculdade de Ciências e Letras Campus de Araraquara, 2014. 
SUMAIO, P. A. Língua terena de sinais: análise descritiva inicial da língua de sinais usada pelos terena da Terra Indígena Cachoeirinha. Tese de Doutorado apresentada ao Programa de Pós-Graduação em Linguística e Língua Portuguesa da Faculdade de Ciências e Letras - Unesp/Araraquara, como requisito para obtenção do título de Doutor em Linguística e Língua Portuguesa. Araraquara - São Paulo, 2018.

VENTURA, M. M. O Estudo de Caso como Modalidade de Pesquisa. SOCERJ. 20(5):383$386,2007$.

VILHALVA, S. Índios Surdos Guarani e Terena em Mato Grosso do Sul: Dez Anos Projeto Índio Surdo e seus Desafios Familiares, Educacionais e Linguísticos. INES Revista Espaço, Rio de Janeiro, n. 50, 2018. Disponível em: <http://www.ines.gov.br/ seer/index.php/revista-espaco/article/view/451/488>. Acesso em: 29 ago. 2019. 